\title{
Pharmacogenetic testing affects choice of therapy among women considering tamoxifen treatment
}

Wendy Lorizio 1,2,3* , Hope Rugo ${ }^{3,4}$, Mary S Beattie ${ }^{1,3,5,6}$, Simone Tchu' ${ }^{7}$, Teri Melese ${ }^{3,8}$, Michelle Melisko ${ }^{3,4}$, Alan HB Wu ${ }^{9}, \mathrm{H}$ Jeffrey Lawrence ${ }^{10}$, Michele Nikoloff ${ }^{10}$ and Elad Ziv $^{1,3,5,6}$

\begin{abstract}
Background: Pharmacogenetic testing holds major promise in allowing physicians to tailor therapy to patients based on genotype. However, there is little data on the impact of pharmacogenetic test results on patient and clinician choice of therapy. CYP2D6 testing among tamoxifen users offers a potential test case of the use of pharmacogenetic testing in the clinic. We evaluated the effect of CYP2D6 testing in clinical practice to determine whether genotype results affected choice of hormone therapy in a prospective cohort study.

Methods: Women planning to take or currently taking tamoxifen were considered eligible. Participants were enrolled in an informational session that reviewed the results of studies of CYP2D6 genotype on breast cancer recurrence. CYP2D6 genotyping was offered to participants using the AmpliChip CYP450 Test. Women were classified as either poor, intermediate, extensive or ultra-rapid metabolizers. Results were provided to clinicians without specific treatment recommendations. Follow-up was performed with a structured phone interview 3 to 6 months after testing to evaluate changes in medication.

Results: A total of 245 women were tested and 235 completed the follow-up survey. Six of 13 (46\%) women classified as poor metabolizers reported changing treatment compared with 11 of 218 (5\%) classified as intermediate, extensive or ultra-rapid metabolizers $(P<0.001)$. There was no difference in treatment choices between women classified as intermediate and extensive metabolizers. In multi-variate models that adjusted for age, race/ethnicity, educational status, method of referral into the study, prior knowledge of CYP2D6 testing, the patients' CYP2D6 genotype was the only significant factor that predicted a change in therapy (odds ratio 22.8; 95\% confidence interval 5.2 to 98.8). Genetic testing did not affect use of co-medications that interact with CYP2D6.

Conclusions: CYP2D6 genotype testing led to changes in therapy among poor metabolizers, even in the absence of definitive data that an alternative medicine improved outcomes. Pharmacogenetic testing can affect choice of therapy, even in the absence of definitive data on clinical impact.
\end{abstract}

\section{Background}

Pharmacogenetics may improve health outcomes by allowing clinicians to tailor medications to patients' individual genetic profiles. Once the genetic determinants of drug response are identified, additional work will be required to translate these findings into practice [1-3]. One major question regarding the implementation of

\footnotetext{
* Correspondence: wlorizio@medicine.ucsf.edu

'Division of General Internal Medicine, Department of Medicine, University of California San Francisco, 1545 Divisadero Street, Suite 322, San Francisco, CA 94143-0320, USA

Full list of author information is available at the end of the article
}

pharmacogenetic testing is how clinicians will incorporate the results into practice and whether the genotypic results will lead to a change in therapy.

Tamoxifen, a selective estrogen receptor modulator, acts as an estrogen receptor antagonist in breast tissue. In the adjuvant setting, tamoxifen reduces breast cancer recurrence [4] and mortality [5,6] among women with hormone receptor-positive breast cancer. Tamoxifen also reduces the risk of breast cancer in high risk women [7]. It is metabolized to 4-hydroxy-N-desmethyltamoxifen, also known as endoxifen [8-10], which is 
considered the primary pharmacologically active metabolite of tamoxifen [9-11]. Cytochrome P450 2D6 enzyme (CYP2D6) is the rate-limiting enzyme that converts $\mathrm{N}$-desmethyl-tamoxifen into endoxifen $[10,12,13]$.

The CYP2D6 gene is highly polymorphic and has several alleles that decrease or completely abolish its enzymatic activity. Several studies suggest that breast cancer patients on tamoxifen with a 'poor metabolizer' phenotype (two inactive alleles) [11,14-18] or with two alleles with reduced enzymatic activity [16,19-24] have a higher rate of breast cancer recurrence compared to patients with other phenotypes. Recent retrospective analyses from two large randomized trials comparing tamoxifen with aromatase inhibition as treatment for early stage breast cancer in post-menopausal women demonstrated no impact of CYP2D6 genotype on outcome $[25,26]$. Nonetheless, the impact of genotype on the effectiveness of tamoxifen remains uncertain [11,13-23,27,28].

Although there is considerable controversy regarding the predictiveness of CYP2D6 genotypes on outcomes, there are alternatives to tamoxifen treatment. Aromatase inhibitors (AIs) are considered more effective at reducing breast cancer recurrence than tamoxifen alone in post-menopausal women with hormone receptor-positive breast cancer [29-33], although no impact has been demonstrated on mortality. In pre-menopausal women with early stage hormone receptor-positive breast cancer, tamoxifen with or without ovarian suppression (OS) remains the preferred treatment for standard adjuvant therapy since no current data demonstrate improved outcomes of pre-menopausal women on AIs plus OS $[34,35]$. However, OS alone or with AIs in pre-menopausal women may be considered an alternative in premenopausal women who do not tolerate tamoxifen [35-37]. Therefore, CYP2D6 testing may be considered a useful test case of the use of pharmacogenetic testing in the clinic since there are alternative treatments.

We prospectively evaluated the effect of CYP2D6 testing in clinical practice and the impact of providing genotype to practitioners and patients in a prospective cohort study. Specifically, we recruited women who had recently started or were considered candidates to start tamoxifen. They were offered CYP2D6 genotype testing and results were sent to the participant's clinician. We then followed women who underwent testing to determine whether the genotypes affected choice of therapy.

\section{Materials and methods Study population}

Potential participants included women who were currently on tamoxifen or who were considered candidates for tamoxifen, either for treatment or prevention of breast cancer. Patients were recruited by physician referral or after receiving a contact letter sent to all patients from the University of California San Francisco (UCSF) Breast Oncology Clinic who met eligibility criteria. Participants were excluded if they could not give informed consent or could not participate in the educational session due to limited English proficiency. Recruitment took place between March 2008 and May 2010. Most of the women, 222, were referred to the study from physicians' offices. Of these, 15 (7\%) did not agree to participate, leaving 207 (93\%) referred women who consented to the study. Another 194 women were contacted by letter. Of those, $102(52 \%)$ did not respond, $54(28 \%)$ said they were not interested $(n=34)$ or not on tamoxifen $(n=20)$, leaving $38(20 \%)$ women who were recruited by letter. Thus, a total of 245 women consented to participate in this study. The institutional review board at UCSF approved the study and all women provided written informed consent at study entry.

\section{Study protocol}

Prior to attending the educational session, each participant was required to identify a referring physician. The referring physician received a short description of the study and agreed to receive the test result in order for the patient to be enrolled. After signing informed consent, the women participated in an educational session conducted by a study physician who used an oral and slideshow presentation to explain genetic testing in general. The study physician also showed slides that included both positive and negative studies regarding CYP2D6 genotype and breast cancer recurrence. The studies discussed included those published prior to March 2008 when recruitment began. The study physician explicitly told participants that genetic testing remains controversial in the medical literature and that additional studies of the utility of genetic testing on clinical outcome were underway. The presentation was approximately 30 to 45 minutes long, including 30 standardized slides and time for questions and discussion. Participants were asked to complete pre- and post-session questionnaires. CYP2D6 testing was offered to all participants at the end of the session (see laboratory protocols) and blood was obtained immediately after the educational component concluded. Results were released to the referring clinician 2 to 4 weeks after testing.

Follow-up was performed with a structured phone interview 3 to 6 months after test results were provided to physicians and patients to determine whether a change in medication occurred.

\section{Demographic, breast cancer risk factors and tamoxifen data collection}

The pre- and post-educational session questionnaires collected the following information: demographics, past medical history, breast cancer history (including 
pathology and prior treatment), tamoxifen use, other comedication use, knowledge of genetic testing, and attitudes towards uptaking new technology. Women were classified as pre-menopausal if they indicated having a menstrual period in the prior 3 months and no change in menstrual regularity in the prior year; they were considered post-menopausal if they had no vaginal bleeding (amenorrhea) for at least 6 months without other obvious pathological or physiological cause. Participants were asked if they were experiencing hot flashes, vaginal dryness, sleep problems and any other side effects from tamoxifen. The number, intensity, duration, and severity of hot flashes were reported in the questionnaire. Severity of each side effect was rated on a Likert scale with responses ranging from 1 (mild) to 5 (extremely severe).

\section{Laboratory procedures}

If the participant agreed to testing, two $10 \mathrm{cc}$ tubes of blood were drawn. One tube of blood was used for genomic DNA extraction that was performed at the UCSF Clinical Pharmacogenomics Laboratory. DNA was extracted from whole blood using the Qiagen QIAamp Blood DNA Kit (Frederick, MD, USA). After extraction, DNA was quantified and stored at $-20^{\circ} \mathrm{C}$. A second blood sample was collected in a serum separator tube and stored at $-20^{\circ} \mathrm{C}$ to measure tamoxifen metabolites, especially endoxifen levels. Tamoxifen metabolite measurements were not reported to patients or clinicians since there were no clinical data on their use at the time the study was conceived and designed.

\section{CYP2D6 genotype}

The analysis of CYP2D6 polymorphisms was performed at the UCSF Clinical Pharmacogenomics Laboratory, a Clinical Laboratory Improvement Amendments Act (CLIA)-certified laboratory, using the AmpliChip CYP450 Test (Roche Molecular Systems, Inc., Branchburg, NJ, USA). This test uses the Affymetrix microarray platform and screens for 27 different alleles of the $C Y P 2 D 6$ gene (including gene duplications and deletions) and 3 alleles of the CYP2C19 gene. The AmpliChip CYP450 Data Analysis Software was used to infer the genotype, and to predict the individual's CYP2D6 enzymatic activity. We classified subjects into four classes: ultra-rapid metabolizers (UMs), extensive metabolizers (EMs), intermediate metabolizers (IMs), and poor metabolizers (PMs). The test and assay conditions for this study followed the manufacturer's instructions [38]. In approximately 1 to $2 \%$ of samples, the test results in a 'no genotype' call, presumably because of a rare variant not detected by the chip that interferes with the usual hybridization patterns. In every case of a 'no genotype' result from the AmpliChip, we repeated the assay at least once to confirm that the result could not be obtained.

\section{Reporting of results}

Clinicians were informed of test results, including the specific genotype and metabolizing status but no specific treatment recommendation was provided. Results were reported with the specific genotype (for example, ${ }^{*} 1 / * 4$ ) and the interpretation of the enzymatic activity as classified by the AmpliChip CYP450 Test (for example, 'ultra-rapid metabolizer', 'extensive metabolizer', 'intermediate metabolizer', or 'poor metabolizer'). We used Table 2 from the AmpliChip package insert for the assignment of ultra-rapid, extensive, intermediate and poor CYP2D 6 metabolizers. In addition, information about the effect of metabolizer status on endoxifen levels and the effect of co-medications was provided based on a commonly used reference [39]. Clinicians were not provided specific input about the relationship between genotype or metabolizer status and breast cancer recurrence because of the controversial nature of this association. Clinicians were provided with a form letter to help with informing patients that offered two possible recommendations: (a) to continue current therapy or (b) to call the clinician and schedule an appointment to discuss the results. The CYP2C19 genotypes from the Amplichip test and endoxifen levels were not part of the main study and these results were not, therefore, reported to attending oncologists.

\section{Clinical follow-up}

Three to six months after CYP2D6 testing, a follow-up questionnaire was administered by a trained research assistant during a structured telephone interview. This questionnaire ascertained whether the patients received the CYP2D6 test result letter and discussed CYP2D6 phenotype status (UM, EM, IM, PM) with their clinician, whether the clinician suggested any change in medication based on the test result (tamoxifen, AIs, or any other medication), and what change was suggested. We also determined whether the patients were still taking, started taking, or stopped taking tamoxifen since study participation and what the reason was for any change in hormone therapy.

\section{Statistical analysis}

To evaluate the effect of CYP2D6 testing in clinical practice and to determine whether reported CYP2D6 phenotype affects change in therapy, we compared the rate of medication change among women identified as PM to women identified as UM, EM or IM using Fisher's exact test. In our analysis, data from women with UM and EM phenotype was combined into one category 
(UM/EM) since all reports suggest that they have the same clinical outcome. All analyses were conducted with the program STATA (version 10, StataCorp LP, College Station, TX, USA).

\section{Results}

A total of 245 women were enrolled in the study, of whom 235 (96\%) participated in the follow-up survey. Ten women (4\%) did not return letters or telephone calls and were not included in the analysis of follow-up. The average age of women enrolled in the study was 47 years (range from 23 to 82; Table 1). Most of the participants were Caucasian (68\%) and Asian (23\%). Thirtyeight percent of women had other chronic health problems. Seventy-two percent of women were married. Educational attainment and income were high; $43 \%$ had completed post-graduate degrees and $44 \%$ lived in households with $>\$ 100,000$ income. At the time of breast cancer diagnosis, 78\% (184) were pre-menopausal and $22 \%$ (51) were post-menopausal. Nearly all of the women enrolled in the study (97\%) had either invasive breast cancer or ductal carcinoma in situ (DCIS) with the majority $(70 \%)$ reporting invasive breast cancer.

Sixty-eight percent (166) of women in the study were taking tamoxifen at the time of enrollment for a median duration of 5 months (range from 1 to 60). The most common side effects attributed to tamoxifen were hot flashes (63\%), sleep problems (46\%) and vaginal dryness (37\%). Approximately $10 \%$ of women (24) in the study reported taking selective serotonin reuptake inhibitors (SSRIs), but only one was taking an SSRI considered to be a strong inhibitor of CYP2D6 (paroxetine). In addition, eight participants (3\%) were taking a moderate to potent inhibitor, the norepinephrine-dopamine inhibitor buproprion.

The primary referral method in the study was by a physician or nurse $(80 \%)$. The rest of the participants were either self-referred or referred by a breast cancer support group (4\%) or recruited by the study contact letter (16\%). Approximately 50\% (122) of the women in the study had previous knowledge of CYP2D6 testing and the main source of this knowledge was a physician or nurse $(38 \%)$. Other sources of prior knowledge regarding testing included women who reported reading about CYP2D6 in the medical literature (20\%), the internet (14\%), and television or newspapers (5\%).

Table 2 shows the detailed CYP2D6 genotypes and predicted phenotype frequency distribution of participants in the study by ethnicity. Of the 245 participants, $4 \%$ (10) were UMs, $76 \%$ (185) were EMs, $13 \%$ (32) IMs and 5\% (13) were PMs. In addition, in four of the women (2\%), we could not ascertain the genotype based on the AmpliChip result (Table 2). Of the 13 PMs, 10 (77\%) were Caucasian, 2 (15\%) were Latina and 1 (8\%) was Asian. There was no significant difference in the rate of PMs across these racial/ethnic categories. Of the 32 IMs, 15 (47\%) were Asian, 15 were Caucasian and 2 (6\%) were Latina. Asians were more likely to be classified as IMs compared to Caucasians $(P=0.002)$. Out of 166 women taking tamoxifen at the time of enrollment, 5 were UMs, 125 EMs, 24 IMs, 7 PMs and 5 'no genotype'.

We found a significant association between CYP2D6 phenotype results and change in therapy (Table 3). Six of the 13 PMs (46\%) changed treatment to an AI, compared to 10 out of 186 in the UM/EM group $(P<$ $0.001)$. In contrast, there was no significant difference in treatment change rates between the women classified as IMs, 1 (3\%, pre-menopausal) out of 32 , and UMs/EMs $(P=0.51)$. In addition, all four women with 'no genotype' call were taking tamoxifen at the time of followup, which was no different than the proportion of women taking tamoxifen among UMs/EMs.

Among the subset of pre-menopausal women $(n=$ 183), 5 of 11 women with the PM phenotype switched to an $\mathrm{AI}$ and $\mathrm{OS}$, which was significantly higher $(P=$ $0.001)$ than the rate of change among the UMs/EMs (5 of 149). There was no difference among women with the UM/EM versus IM phenotype when we analyzed the pre-menopausal women $(P=0.54)$.

A total of 26 women reported that they were not taking hormone therapy at the time of follow-up. Of these women, four (three EMs and one IM, all pre-menopausal) were considering tamoxifen for prevention, seven (six EMs and one IM) were considering tamoxifen for treatment of DCIS and six (five EMs and one IM) for treatment of invasive breast cancer. There was no difference in the probability of being on or off hormone therapy by CYP2D6 metabolizer status.

Of the $186 \mathrm{UMs} / \mathrm{EMs}, 21 \%$ (38) were taking one or more co-medications at the time of enrollment. Nine of these 38 women $(24 \%)$ changed or stopped a co-medication at the time of follow-up. Of the women on the most potent inhibitors, two of nine stopped a co-medication. There was no significant difference in the rate of change of co-medication between IMs compared to UMs/EMs $(P=0.62)$. None of the PMs were taking any of the co-medications and CYP2D6 inhibitors described in Table 1.

We also evaluated whether any factors besides CYP2D6 genotype predict change in therapy (Table 4). In univariate analyses there was no association between change to AIs and method of referral or previous knowledge of CYP2D6 testing. Among women who said they had prior knowledge, the source of knowledge (physician versus medical literature versus internet) did not affect choice of therapy. We also found no association between change in therapy and report of interest in 
Table 1 Demographics, breast cancer, tamoxifen use and co-medications use characteristics in the overall population in the study

\begin{tabular}{|c|c|c|}
\hline Characteristics $(N=245)$ & $\mathrm{N} /$ mean & Percent/SD \\
\hline Mean age (years) ${ }^{a}$ & 47.46 & \pm 9.7 \\
\hline \multicolumn{3}{|l|}{ Self-report ethnicity } \\
\hline Caucasian & 166 & 67.76 \\
\hline Asian/East Asian & 56 & 22.86 \\
\hline African American/Black & 2 & 0.82 \\
\hline Latina/Hispanic & 14 & 5.71 \\
\hline Pacific Islander & 1 & 0.41 \\
\hline Other/mixed & 3 & 1.22 \\
\hline Declined/refused/do not know & 3 & 1.22 \\
\hline Number married (yes) & 176 & 72 \\
\hline Number full-time working & 98 & 40 \\
\hline \multicolumn{3}{|l|}{ Education levels } \\
\hline High school graduated or less & 6 & 2.45 \\
\hline Some college & 36 & 14.69 \\
\hline College graduated & 90 & 36.73 \\
\hline Completed post-graduate degree & 105 & 42.86 \\
\hline Declined/refused & 8 & 3.27 \\
\hline \multicolumn{3}{|l|}{ Socio-economic status } \\
\hline Income $<\$ 50,000$ & 29 & 11.84 \\
\hline Income $\geq \$ 50,000$ to $<\$ 100,000$ & 56 & 22.86 \\
\hline Income $\geq \$ 100,000$ & 108 & 44.07 \\
\hline Declined/refused & 52 & 21.23 \\
\hline Reported other health problems & 91 & 38 \\
\hline \multicolumn{3}{|l|}{ Breast cancer characteristics } \\
\hline Breast cancer (yes) & 237 & 97 \\
\hline Had invasive breast cancer & 165 & 70 \\
\hline Surgery (yes) & 231 & 98 \\
\hline Had lumpectomy & 119 & 52 \\
\hline \multicolumn{3}{|l|}{ Menopausal status at diagnosis } \\
\hline Pre-menopausal & 184 & 78 \\
\hline Post-menopausal & 51 & 22 \\
\hline Mean age at menopause (years) ${ }^{a}$ & 45.61 & \pm 6.79 \\
\hline Had natural menopause & 35 & 22.73 \\
\hline Menopause due to chemotherapy treatment & 74 & 48.05 \\
\hline Previous used of hormone therapy & 37 & 15 \\
\hline \multicolumn{3}{|l|}{ Tamoxifen use } \\
\hline Ever prescribed & 191 & 78 \\
\hline Ever taken & 171 & 70 \\
\hline Currently taking & 166 & 68 \\
\hline \multicolumn{3}{|l|}{ Common side effects attributed to tamoxifen } \\
\hline Hot flashes & 154 & 63 \\
\hline Sleep problems & 113 & 46 \\
\hline Vaginal dryness & 90 & 37 \\
\hline \multicolumn{3}{|l|}{ Co-medications/CYP2D6 inhibitors } \\
\hline \multicolumn{3}{|l|}{ Strong inhibitors } \\
\hline Paroxetine & 1 & 0.41 \\
\hline Bupropion & 8 & 3.26 \\
\hline \multicolumn{3}{|l|}{ Moderate inhibitors } \\
\hline Sertraline & 8 & 3.26 \\
\hline Duloxetine & 3 & 1.22 \\
\hline
\end{tabular}



in the study (Continued)

\begin{tabular}{|c|c|c|}
\hline \multicolumn{3}{|l|}{ All other inhibitors } \\
\hline Amitriptyline & 2 & 0.82 \\
\hline Amlodipine & 2 & 0.82 \\
\hline Celecoxib & 2 & 0.82 \\
\hline Ceterizine & 2 & 0.82 \\
\hline Citalopram & 6 & 2.45 \\
\hline Diphenhydramine & 3 & 1.22 \\
\hline Escitalopram & 6 & 2.45 \\
\hline Imipramine & 1 & 0.41 \\
\hline Loratadine & 3 & 1.22 \\
\hline Nortriptyline & 1 & 0.41 \\
\hline Ranitidine & 1 & 0.41 \\
\hline \multicolumn{3}{|l|}{ Other co-medications } \\
\hline Gabapentin & 10 & 4.00 \\
\hline Trazodone & 2 & 0.82 \\
\hline Venlafaxine & 15 & 6.12 \\
\hline \multicolumn{3}{|l|}{ Referral method } \\
\hline Physician/nurse referral & 196 & 80 \\
\hline Self-referred or breast cancer support group referral & 11 & 4 \\
\hline Study contact letter & 38 & 16 \\
\hline Previous knowledge of CYP2D6 testing (yes) & 122 & 50 \\
\hline \multicolumn{3}{|l|}{ Source of CYP2D6 testing knowledge } \\
\hline Physician or nurse & 46 & 38 \\
\hline Newspaper & 5 & 4 \\
\hline Television & 1 & 1 \\
\hline Internet & 17 & 14 \\
\hline Medical literature & 24 & 20 \\
\hline Other & 27 & 22 \\
\hline Unknown/missed & 2 & 1 \\
\hline
\end{tabular}

${ }^{a}$ Data presented as mean \pm SD. $N$, number of participants in the study; SD, standard deviation.

CYP2D6 testing $(P=0.34)$ or report of interest in new medical treatments and technology $(P=0.59)$. In addition, age, race/ethnicity and education were not predictive of change in therapy (results not shown). No other significant associations were found. Specifically, age, menopausal status, educational attainment, race/ethnicity and indication for treatment (invasive cancer versus carcinoma in situ versus prevention) did not predict change in therapy in univariate analyses. There was no association between change in hormone therapy and reported side effects from tamoxifen.

We used multi-variate models to determine whether any factors may confound the association between CYP2D 6 genotype and change in therapy (Table 4). $C Y P 2 D 6$ genotype remained the only statistically significant association with change in therapy even after adjustment for age, breast cancer type (invasive breast cancer, DCIS and lobular carcinoma in situ (LCIS)), menopausal status (pre-menopausal versus post-menopausal), report of any tamoxifen-induced side effects, previous knowledge of CYP2D6 testing, referral method (physician or nurse versus other sources) and interest in CYP2D6 testing.

\section{Discussion}

We provided CYP2D6 genotype results to clinicians and patients and evaluated the impact of this information on the proportion of women who changed hormone therapy. Approximately 5\% of women were PMs and 6 out of $13(46 \%)$ changed treatment after discussion with their physicians. This was a significantly higher percentage than the rate of therapy change in those with UM, EM or IM phenotypes, suggesting that in this setting phenotype results affected treatment decisions. The association between medication change was not confounded by method of referral to the study or by prior interest in CYP2D6 testing.

For pre-menopausal women, change in hormone therapy included both an AI as well as ovarian suppression that leads to significant side effects associated with early 
Table 2 Distribution of CYP2D6 genotype and predicted phenotype by different ethnic groups

\begin{tabular}{|c|c|c|c|c|c|c|c|c|}
\hline \multirow[b]{2}{*}{$\begin{array}{l}\text { CYP2D6 predicted phenotype/ } \\
\text { genotype }\end{array}$} & \multicolumn{7}{|c|}{ Ethnicity } & \multirow[b]{2}{*}{$\begin{array}{c}\text { Total N } \\
(\%)\end{array}$} \\
\hline & Caucasian & $\begin{array}{l}\text { Latina/ } \\
\text { Hispanic }\end{array}$ & $\begin{array}{l}\text { AA/ } \\
\text { Black }\end{array}$ & Asian & $\begin{array}{c}\text { Pacific } \\
\text { Islander }\end{array}$ & $\begin{array}{l}\text { Other/ } \\
\text { mixed }\end{array}$ & $\begin{array}{c}\text { Declined/ } \\
\text { missed }\end{array}$ & \\
\hline Ultra-rapid (UM) & $8(5 \%)$ & $1(7 \%)$ & 0 & $1(2 \%)$ & 0 & 0 & 0 & $10(4 \%)$ \\
\hline$*^{*} 1 / *^{*} \times N$ & 5 & 0 & 0 & 0 & 0 & 0 & 0 & 5 \\
\hline${ }^{*} 1 /{ }^{*} 2 \times N$ & 1 & 1 & 0 & 0 & 0 & 0 & 0 & 2 \\
\hline${ }^{*} 2 /{ }^{*} 1 \times N$ & 1 & 0 & 0 & 1 & 0 & 0 & 0 & 2 \\
\hline${ }^{*} 2 /{ }^{*} 2 \times N$ & 1 & 0 & 0 & 0 & 0 & 0 & 0 & 1 \\
\hline Extensive (EM) & $\begin{array}{c}131 \\
(79 \%)\end{array}$ & $9(65 \%)$ & $\begin{array}{c}2 \\
(100 \%)\end{array}$ & $\begin{array}{c}36 \\
(64 \%)\end{array}$ & $1(100 \%)$ & $3(100 \%)$ & $3(100 \%)$ & 185 (76\%) \\
\hline$*^{*} 1 /{ }^{*} 1$ & 19 & 2 & 1 & 2 & 1 & 1 & 0 & 26 \\
\hline$*^{*} 1 /{ }^{*} 2$ & 20 & 0 & 0 & 5 & 0 & 0 & 0 & 25 \\
\hline$* 1 / * 3$ & 2 & 0 & 0 & 0 & 0 & 0 & 0 & 2 \\
\hline$* 1 / * 4$ & 23 & 1 & 0 & 1 & 0 & 0 & 1 & 26 \\
\hline$* 1 / * 5$ & 3 & 0 & 0 & 1 & 0 & 1 & 0 & 5 \\
\hline${ }^{*} 1 /{ }^{*} 6$ & 1 & 0 & 0 & 0 & 0 & 0 & 0 & 1 \\
\hline$*^{*} 1 / *^{*}$ & 4 & 2 & 0 & 0 & 0 & 0 & 0 & 6 \\
\hline$* 1 /{ }^{*} 10$ & 1 & 0 & 0 & 15 & 0 & 0 & 0 & 16 \\
\hline$* 1 / * 17$ & 1 & 0 & 1 & 0 & 0 & 0 & 0 & 2 \\
\hline$* 1 / * 29$ & 0 & 0 & 0 & 0 & 0 & 0 & 1 & 1 \\
\hline$* 1 / * 35$ & 2 & 0 & 0 & 0 & 0 & 0 & 0 & 2 \\
\hline$* 1 / * 41$ & 16 & 1 & 0 & 1 & 0 & 0 & 0 & 18 \\
\hline$* 1 \times N / * 5$ & 1 & 0 & 0 & 0 & 0 & 0 & 0 & 1 \\
\hline${ }^{*} 1 \times N /{ }^{*} 10$ & 0 & 0 & 0 & 1 & 0 & 0 & 0 & 1 \\
\hline$* 2 /{ }^{*} 2$ & 5 & 0 & 0 & 0 & 0 & 0 & 0 & 5 \\
\hline${ }^{*} 2 / *^{*}$ & 11 & 1 & 0 & 0 & 0 & 0 & 1 & 13 \\
\hline$* 2 / * 5$ & 1 & 0 & 0 & 0 & 0 & 0 & 0 & 1 \\
\hline$* 2 /{ }^{*} 9$ & 1 & 0 & 0 & 0 & 0 & 0 & 0 & 1 \\
\hline$* 2 /{ }^{*} 10$ & 0 & 1 & 0 & 10 & 0 & 0 & 0 & 11 \\
\hline$* 2 / * 35$ & 3 & 0 & 0 & 0 & 0 & 0 & 0 & 3 \\
\hline$* 2 /{ }^{*} 41$ & 5 & 0 & 0 & 0 & 0 & 0 & 0 & 5 \\
\hline${ }^{*} 2 /{ }^{*} 41 \times N$ & 1 & 0 & 0 & 0 & 0 & 0 & 0 & 1 \\
\hline$*^{*} 2 \times N /{ }^{*} 4$ & 1 & 0 & 0 & 0 & 0 & 0 & 0 & 1 \\
\hline${ }^{*} 2 \times N / * 9$ & 1 & 0 & 0 & 0 & 0 & 0 & 0 & 1 \\
\hline$* 3 / * 35$ & 1 & 0 & 0 & 0 & 0 & 0 & 0 & 1 \\
\hline$* 4 / * 35$ & 5 & 0 & 0 & 0 & 0 & 0 & 0 & 5 \\
\hline$* 5 / * 35$ & 0 & 1 & 0 & 0 & 0 & 0 & 0 & 1 \\
\hline$* 10 / * 35$ & 1 & 0 & 0 & 0 & 0 & 0 & 0 & 1 \\
\hline$* 17 / * 35$ & 0 & 0 & 0 & 0 & 0 & 1 & 0 & 1 \\
\hline$* 35 / * 41$ & 1 & 0 & 0 & 0 & 0 & 0 & 0 & 1 \\
\hline${ }^{*} 35 /{ }^{*} 41 \times N$ & 1 & 0 & 0 & 0 & 0 & 0 & 0 & 1 \\
\hline Intermediate (IM) & $15(9 \%)$ & $2(14 \%)$ & 0 & $\begin{array}{c}15 \\
(27 \%)\end{array}$ & 0 & 0 & 0 & $32(13 \%)$ \\
\hline$* 4 /{ }^{*} 9$ & 1 & 0 & 0 & 0 & 0 & 0 & 0 & 1 \\
\hline$* 4 /{ }^{*} 10$ & 2 & 0 & 0 & 0 & 0 & 0 & 0 & 2 \\
\hline$* 4 /{ }^{*} 17$ & 1 & 0 & 0 & 0 & 0 & 0 & 0 & 1 \\
\hline$* 4 / * 41$ & 6 & 1 & 0 & 0 & 0 & 0 & 0 & 7 \\
\hline$*^{*} /{ }^{*} 10$ & 1 & 0 & 0 & 2 & 0 & 0 & 0 & 3 \\
\hline${ }^{*} 10 /{ }^{*} 10$ & 0 & 0 & 0 & 13 & 0 & 0 & 0 & 13 \\
\hline$* 10 / * 41$ & 2 & 0 & 0 & 0 & 0 & 0 & 0 & 2 \\
\hline$* 29 / * 41$ & 0 & 1 & 0 & 0 & 0 & 0 & 0 & 1 \\
\hline
\end{tabular}


Table 2 Distribution of CYP2D6 genotype and predicted phenotype by different ethnic groups (Continued)

\begin{tabular}{|c|c|c|c|c|c|c|c|c|}
\hline$* 41 / * 41$ & 2 & 0 & 0 & 0 & 0 & 0 & 0 & 2 \\
\hline Poor (PM) & $10(6 \%)$ & $2(14 \%)$ & 0 & $1(2 \%)$ & 0 & 0 & 0 & $13(5 \%)$ \\
\hline${ }^{*} 3 /{ }^{*} 4$ & 1 & 0 & 0 & 0 & 0 & 0 & 0 & 1 \\
\hline$* 4 / * 4$ & 7 & 0 & 0 & 1 & 0 & 0 & 0 & 8 \\
\hline$* 4 / * 5$ & 0 & 2 & 0 & 0 & 0 & 0 & 0 & 2 \\
\hline${ }^{*} 4 /{ }^{*} 6$ & 1 & 0 & 0 & 0 & 0 & 0 & 0 & 1 \\
\hline$*^{*} / *^{*} 7$ & 1 & 0 & 0 & 0 & 0 & 0 & 0 & 1 \\
\hline No genotype & $2(1 \%)$ & 0 & 0 & $3(5 \%)$ & 0 & 0 & 0 & $5(2 \%)$ \\
\hline Total & 166 & 14 & 2 & 56 & 1 & 3 & 3 & 245 \\
\hline
\end{tabular}

AA, African American; EM, extensive metabolizer; IM, intermediate metabolizer; N, number of participants in the study; PM, poor metabolizer; UM, ultra-rapid metabolizer.

menopause. Thus, despite the limited evidence and the risk of side effects from an alternative treatment, physicians and patients frequently changed therapy in response to a PM phenotype. Treatment with an AI alone in younger women who have amenorrhea due to chemotherapy may lead to inadequate hormonal suppression [40]. We did not directly make any treatment recommendations. But five of the six women who had changed to an AI also received OS. The only woman who received AI alone was aged 56 years and was known to be post-menopausal prior to breast cancer treatment. Therefore, the physicians who referred to our study appear to be aware of the risks of inadequate hormonal therapy and to have used combination therapy when appropriate.

The association between CYP2D6 genotype and efficacy of tamoxifen in women with early stage, hormone receptor-positive breast cancer remains unclear. CYP2D6 activity clearly correlates with endoxifen levels, but the association with outcome has been far more controversial. Several studies have demonstrated an association [11,14-19], but other studies, including the two largest, have failed to confirm an impact of enzyme activity and breast cancer outcome [20-23,25,26]. A recent meta-analysis found a trend towards association between CYP2D6 genotype and disease free survival but not overall survival [41]. However, the authors noted considerable heterogeneity among the studies in both the reported associations and in the way subsets of genotypes were grouped. More recently, two large randomized controlled trials, the Arimidex, Tamoxifen, Alone or in Combination (ATAC) trial [25] and the Breast International Group (BIG) 1-98 trial [26], evaluated the impact of CYP2D6 polymorphisms in patients treated with tamoxifen. Neither study demonstrated an association between the risk of breast cancer recurrence and CYP2D6 phenotype.

Our study had completed all the enrollment and the follow-up by September 2010, prior to the presentation of the genotyping data from the ATAC and BIG 1-98 trials in December 2010. Thus, at the time that patients and clinicians were deciding how to interpret the genotypes, these results could not be taken into consideration, but could have a significant impact on decisions regarding testing and treatment change. However, as part of our presentation to patients prior to testing, we showed the results of both prior positive and negative studies testing for associations between CYP2D6 and breast cancer. Since physicians and patients were aware of the controversial results, our study demonstrates that many clinicians and patients are generally willing to make treatment decisions even in the curative setting

Table 3 Association of CYP2D6 testing and therapeutic decision-making by CYP2D6 phenotypes

\begin{tabular}{|c|c|c|c|c|c|c|c|c|}
\hline CYP2D6 phenotype & $\begin{array}{c}\text { Still on } \\
\text { tamoxifen }\end{array}$ & $\begin{array}{l}\text { Changed to } \\
\text { Als }\end{array}$ & $\begin{array}{l}\text { No } \\
\text { therapy }\end{array}$ & Total & $P^{\mathrm{a}}$ & $\begin{array}{l}\text { Taking co- } \\
\text { medications }\end{array}$ & $\begin{array}{l}\text { Changed co- } \\
\text { medication }\end{array}$ & $P^{a}$ \\
\hline $\begin{array}{l}\text { Ultra-rapid (UM)/extensive } \\
\text { metabolizer (EM) }\end{array}$ & 156 (84\%) & $10(5 \%)$ & 20 (11\%) & 186 & & 38 (21\%) & $9(5 \%)$ & \\
\hline Intermediate metabolizer (IM) & $28(88 \%)$ & $1(3 \%)$ & $3(9 \%)$ & 32 & 0.51 & $8(25 \%)$ & $2(3 \%)$ & 0.62 \\
\hline Poor metabolizer (PM) & $4(31 \%)$ & $6(46 \%)$ & $3(23 \%)$ & 13 & $\begin{array}{c}< \\
0.001\end{array}$ & 0 & 0 & - \\
\hline Total & 188 & 17 & 26 & 231 & & 46 & 11 & \\
\hline
\end{tabular}

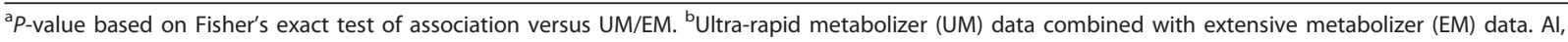
aromatase inhibitor. 
Table 4 Association of therapeutic decision-making by clinical and breast cancer characteristics, CYP2D6 phenotype, previous knowledge of CYP2D6 testing, referral method, and interest in CYP2D6 testing

\begin{tabular}{|c|c|c|}
\hline \multirow[b]{3}{*}{ Characteristics } & \multicolumn{2}{|c|}{ Change to aromatase inhibitors } \\
\hline & Unadjusted & Adjusted $^{\mathrm{a}}$ \\
\hline & OR $(95 \% \mathrm{Cl}) P$-value & OR $(95 \% \mathrm{Cl}) P$-value \\
\hline Age & $1.03(0.98,1.08) 0.23$ & $1.02(0.95,1.10) 0.50$ \\
\hline \multicolumn{3}{|l|}{ Breast cancer type } \\
\hline Invasive breast cancer & - & - \\
\hline Ductal carcinoma in situ (DCIS) & $1.07(0.32,3.48) 0.90$ & $1.33(0.34,5.11) 0.67$ \\
\hline Lobular carcinoma in situ (LCIS) & $0.82(0.09,6.76) 0.85$ & $0.44(0.03,5.59) 0.53$ \\
\hline Post-menopausal status & $1.54(0.51,4.62) 0.43$ & $1.78(0.35,9.08) 0.48$ \\
\hline Report of any tamoxifen side effects (yes) & $1.09(0.34,3.50) 0.87$ & $0.61(0.16,2.31) 0.47$ \\
\hline \multicolumn{3}{|l|}{ CYP2D6 phenotype } \\
\hline UM/EM ${ }^{b}$ & - & - \\
\hline IM & $0.56(0.07,4.59) 0.59$ & $0.38(0.04,3.38) 0.38$ \\
\hline PM & $\begin{array}{l}15.08(4.26,53.33) \\
0.0001\end{array}$ & $\begin{array}{l}22.85(5.28,98.74) \\
0.0001\end{array}$ \\
\hline Previous knowledge of CYP2D6 testing (yes) & $0.88(0.33,2.38) 0.81$ & $0.91(0.29,2.84) 0.87$ \\
\hline Referred by physician or nurse (yes) & $0.60(0.20,1.81) 0.37$ & $0.36(0.09,1.37) 0.13$ \\
\hline $\begin{array}{l}\text { Very interested in CYP2D6 testing before attending the educational session (versus somewhat and } \\
\text { not really interested) }\end{array}$ & $1.77(0.49,6.38) 0.38$ & $3.01(0.66,13.65) 0.15$ \\
\hline
\end{tabular}

The number of participants followed up was $235 .{ }^{a}$ Odd ratios adjusted for age, breast cancer type, menopausal status, report of any tamoxifen side effects, CYP2D6 phenotype, previous knowledge of CYP2D6 testing, referral method, and interest in CYP2D6 testing. P-value $\leq 0.05$. ${ }^{b} U 1$ tra-rapid metabolizer (UM) data combined with extensive metabolizer (EM) data. Cl, confidence interval; DCIS, ductal carcinoma in situ; EM, extensive metabolizer; IM, intermediate metabolizer; LCIS, lobular carcinoma in situ; N, number of participants; OR, odds ratio; PM, poor metabolizer; UM, ultra-rapid metabolizer.

based on non-definitive and retrospective pharmacogenetic information when accompanied by a reasonable hypothesis.

The prevalence of CYP2D6 polymorphisms varies across ethnic groups. The frequency of CYP2D6 PMs in our study is consistent with previous reports $[15,19]$. Like other investigators $[14,24,42]$, we found that the most frequent variant present in Asians was CYP2D6*10, an allele with reduced activity. Results examining the association between the " 10 allele and clinical outcomes have also been mixed $[14,16,19,20,24,42]$. The rate of medication change among patients with the IM CYP2D6 phenotype, including patients homozygous for this allele, was similar to that in patients with the UM/EM phenotype, suggesting that physicians do not consider these patients at significantly increased risk of recurrence.

Endoxifen concentration varies not only according to the number of functional CYP2D6 alleles [43] but also in the presence of potent $C Y P 2 D 6$ enzyme inhibitors. Agents such as the SSRIs paroxetine or fluoxetine, and the anti-arrhythmic quinidine are among the most potent inhibitors $[9,44]$. When these medications are coadministered with tamoxifen to women with an EM phenotype, endoxifen concentrations are similar to those observed in PM and have the potential, therefore, to reduce tamoxifen efficacy $[9,43,44]$. Other commonly used medications such as buproprion, duloxetine, clomipramine, thioridazine, pherphenazine, and pimozide exhibit inhibition close to that of paroxetine, fluoxetine and quinidine [44-46]. While we found that some women did change their co-medications, this was unrelated to CYP2D6 genotype. Our study did not collect enough information from physicians to distinguish between those two possibilities.

Our study is unique in that, to our knowledge, no prior pharmacogenetic studies on change in therapy for CYP2D6 have been previously published. Several studies have examined the issue of incorporating pharmacogenetic data in dosing warfarin $[47,48]$; however, genetic testing for warfarin dosing does not involve a change to a different medication. Several studies have also shown 
that genetic testing for $B R C A 1 / 2$ leads to selection of risk-reducing surgeries [49-51], the use of post-menopausal hormone therapy [52], and pre-implantation genetic diagnosis [53].

Our study also has several important limitations. First, the evidence for the association between CYP2D6 polymorphisms and outcomes remains mixed in the literature and the availability of the most recent results may have changed the decisions that patients and providers in our study made. Second, our sample may have been biased by referral patterns and by patient participation. Physicians and patients who are interested in testing and in changing therapy based on test results may have been more likely to participate in our study. However, we found no association between prior knowledge or interest in CYP2D6 genotype testing and choice of therapy at follow-up. In addition, there were no other significant predictors within our data. Third, our sample may not be universally generalizable. Our patients tended to be mostly Caucasians and Asians, highly educated on average, with a relatively high income level, and most were already being followed at a University medical center for breast cancer. Furthermore, our study used patient self-report of medication use rather than chart review or physician report. However, both patient report and physician report may have limitations. More studies should be conducted to determine how genotyping results would be used in community settings.

\section{Conclusions}

Our study demonstrates that CYP2D6 pharmacogenetic testing led to change in therapy among patients with genotypes that predicted no CYP2D6 activity. Thus, clinicians and patients do use pharmacogenetic results to change therapy, even in the absence of definitive knowledge about the utility of the pharmacogenetic result. Ultimately, prospective randomized trials will be required to demonstrate the impact of treatment change based on pharmacogenetic testing.

\footnotetext{
Abbreviations

Al: aromatase inhibitor; ATAC: Arimidex, Tamoxifen, Alone or in Combination: BIG: Breast International Group; CYP2C19: cytochrome P450 2C19; CYP2D6: cytochrome P450 2D6; DCIS: ductal carcinoma in situ; EM: extensive metabolizer; IM: intermediate metabolizer; OS: ovarian suppression; PM: poor metabolizer; SSRI: selective serotonin reuptake inhibitor; UCSF: University of California San Francisco; UM: ultra-rapid metabolizer.

\section{Acknowledgements}

This work was supported by the National Institute of General Medical Sciences Award T32 GM007546, University of California San Francisco, Clinical Pharmacology Postdoctoral Fellowship Training to WL; California Breast Cancer Research Program (CBCRP) grant 14OB-0166 to EZ; materials and instrumentation for the AmpliChip CYP450 Test were donated by Roche Molecular Systems, Inc. MSB was supported by the Center for Translational and Policy Research in Personalized Medicine (TRANSPERS) NIH/NCI grant P01 CA130818-02A1. We thank Viktoriya Krepkiy (Ziv Lab), Andrew Smith and
}

Erin Shea (Wu Lab) for helping during the educational sessions, following up participants and genotyping for CYP2D6. We also thank the clinical staff at UCSF Breast Oncology Clinic, as well as the patients for their participation.

\section{Author details}

${ }^{1}$ Division of General Internal Medicine, Department of Medicine, University of California San Francisco, 1545 Divisadero Street, Suite 322, San Francisco, CA 94143-0320, USA. ²Division of Clinical Pharmacology and Experimental Therapeutics, Department of Medicine, University of California San Francisco, San Francisco General Hospital Medical Center, 1001 Potrero Avenue, Building 30, 2nd Floor, Room 3216, San Francisco, CA 94143-1220, USA. ${ }^{3}$ Helen Diller Family Comprehensive Cancer Center, University of California San Francisco, 1600 Divisadero Street, San Francisco, CA 94143, USA. ${ }^{4}$ Division of Hematology and Oncology, Department of Medicine, University of California San Francisco, 1600 Divisadero Street, Room B-608, San Francisco, CA 94143-1710, USA. ${ }^{5}$ Department of Epidemiology and Biostatistics, University of California San Francisco, 185 Berry Street, Lobby 5, Suite 5700, San Francisco, CA 94107, USA. ${ }^{6}$ Institute for Human Genetics, University of California San Francisco, 513 Parnassus Avenue, Suite S965, San Francisco, CA 94143-0794, USA. ${ }^{7}$ Department of Biopharmaceutical Sciences, University of California San Francisco, 1700 Fourth Street, Byers Hall, Suite BH-216, San Francisco, CA 94143-0775, USA. ${ }^{8}$ Department of Medicine, School of Medicine, Dean's Office, University of California San Francisco, 513 Parnassus Avenue, Medical Science Building 224, San Francisco, CA 941430410, USA. ${ }^{9}$ Department of Laboratory Medicine, University of California San Francisco, 1001 Potrero Avenue, SFGH 5 2M27, San Francisco, CA 94143, USA. ${ }^{10}$ Roche Molecular Systems, Inc., 4300 Hacienda Drive, Pleasanton, CA 94588, USA.

\section{Authors' contributions}

WL and EZ participated in the conception, design and implementation of the study, acquisition of data, performed the statistical analysis and interpretation of data, and participated in drafting and preparation of the manuscript. HR, MSB, and MM participated in the conception of the study, acquisition of data and drafting the manuscript. TM provided administrative and institutional support, and participated in drafting the manuscript. ST and AHBW carried out the DNA extraction, CYP2D6 genotype assay and interpretation, and participated in drafting the manuscript. HJL and MN provided technical support and interpretation for the AmpliChip CYP450 Test and Data Analysis Software. All authors read and approved the final version of the manuscript.

\section{Competing interests}

$\mathrm{HJL}$ and MN are full-time employees of Roche Molecular Systems, Inc., which manufactures the AmpliChip CYP450 Test. These authors were not involved in any of the presentations of information to patients regarding the assay either prior to or after testing. They were involved in assisting the UCSF investigators with technical questions regarding the assay, and were involved in critical revisions of the manuscript. The rest of the authors declare that they have no competing interests.

Received: 10 August 2011 Revised: 26 September 2011 Accepted: 4 October 2011 Published: 4 October 2011

\section{References}

1. Pirmohamed M: Acceptance of biomarker-based tests for application in clinical practice: criteria and obstacles. Clin Pharmacol Ther 2010, 88:862-866.

2. Kitzmiller JP, Groen DK, Phelps MA, Sadee W: Pharmacogenomic testing: relevance in medical practice: why drugs work in some patients but not in others. Cleve Clin J Med 2011, 78:243-257.

3. Wong WB, Carlson JJ, Thariani R, Veenstra DL: Cost effectiveness of pharmacogenomics: a critical and systematic review. Pharmacoeconomics 2010, 28:1001-1013.

4. Jordan VC: Tamoxifen: a most unlikely pioneering medicine. Nat Rev Drug Discov 2003, 2:205-213.

5. Group EBCTC: Effects of chemotherapy and hormonal therapy for early breast cancer on recurrence and 15-year survival: an overview of the randomised trials. Lancet 2005, 365:1687-1717.

6. Group EBCTC: Tamoxifen for early breast cancer: an overview of randomized trials. Lancet 1998, 351:1451-1467. 
7. Fisher B, Costantino JP, Wickerham DL, Redmond CK, Kavanah M, Cronin WM, Vogel V, Robidoux A, Dimitrov N, Atkins J, Daly M, Wieand S, Tan-Chiu E, Ford L, Wolmark N: Tamoxifen for prevention of breast cancer: report of the National Surgical Adjuvant Breast and Bowel Project P-1 Study. J Natl Cancer Inst 1998, 90:1371-1388.

8. Lien EA, Solheim E, Lea OA, Lundgren S, Kvinnsland S, Ueland PM: Distribution of 4-hydroxy-N-desmethyltamoxifen and other tamoxifen metabolites in human biological fluids during tamoxifen treatment. Cancer Res 1989, 49:2175-2183.

9. Stearns V, Johnson MD, Rae JM, Morocho A, Novielli A, Bhargava P, Hayes DF, Desta Z, Flockhart DA: Active tamoxifen metabolite plasma concentrations after coadministration of tamoxifen and the selective serotonin reuptake inhibitor paroxetine. J Natl Cancer Inst 2003, 95:1758-1764.

10. Wu X, Hawse JR, Subramaniam M, Goetz MP, Ingle JN, Spelsberg TC: The tamoxifen metabolite, endoxifen, is a potent antiestrogen that targets estrogen receptor alpha for degradation in breast cancer cells. Cancer Res 2009, 69:1722-1727.

11. Jin Y, Desta Z, Stearns V, Ward B, Ho H, Lee KH, Skaar T, Storniolo AM, Li L, Araba A, Blanchard R, Nguyen A, Ullmer L, Hayden J, Lemler S, Weinshilboum RM, Rae JM, Hayes DF, Flockhart DA: CYP2D6 genotype, antidepressant use, and tamoxifen metabolism during adjuvant breast cancer treatment. J Natl Cancer Inst 2005, 97:30-39.

12. Jordan VC, Collins MM, Rowsby L, Prestwich G: A monohydroxylated metabolite of tamoxifen with potent antioestrogenic activity. J Endocrinol 1977, 75:305-316.

13. Desta Z, Ward BA, Soukhova NV, Flockhart DA: Comprehensive evaluation of tamoxifen sequential biotransformation by the human cytochrome P450 system in vitro: prominent roles for CYP3A and CYP2D6. J Pharmacol Exp Ther 2004, 310:1062-1075.

14. Xu Y, Sun $Y$, Yao L, Shi L, Wu Y, Ouyang T, Li J, Wang T, Fan Z, Fan T, Lin B, He L, Li P, Xie Y: Association between CYP2D6*10 genotype and survival of breast cancer patients receiving tamoxifen treatment. Ann Oncol 2008, 19:1423-1429.

15. Bijl MJ, van Schaik RH, Lammers LA, Hofman A, Vulto AG, van Gelder T, Stricker BH, Visser LE: The CYP2D6*4 polymorphism affects breast cancer survival in tamoxifen users. Breast Cancer Res Treat 2009, 118:125-130.

16. Kiyotani K, Mushiroda T, Sasa M, Bando Y, Sumitomo I, Hosono N, Kubo M, Nakamura $Y$, Zembutsu $\mathrm{H}$ : Impact of CYP2D6*10 on recurrence-free survival in breast cancer patients receiving adjuvant tamoxifen therapy. Cancer Sci 2008, 99:995-999.

17. Schroth W, Antoniadou L, Fritz P, Schwab M, Muerdter T, Zanger UM, Simon W, Eichelbaum M, Brauch H: Breast cancer treatment outcome with adjuvant tamoxifen relative to patient CYP2D6 and CYP2C19 genotypes. J Clin Oncol 2007, 25:5187-5193.

18. Goetz MP, Knox SK, Suman VJ, Rae JM, Safgren SL, Ames MM, Visscher DW, Reynolds C, Couch FJ, Lingle WL, Weinshilboum RM, Fritcher EG, Nibbe AM, Desta Z, Nguyen A, Flockhart DA, Perez EA, Ingle JN: The impact of cytochrome P450 2D6 metabolism in women receiving adjuvant tamoxifen. Breast Cancer Res Treat 2007, 101:113-121.

19. Lim HS, Ju Lee H, Seok Lee K, Sook Lee E, Jang IJ, Ro J: Clinical implications of CYP2D6 genotypes predictive of tamoxifen pharmacokinetics in metastatic breast cancer. J Clin Oncol 2007, 25:3837-3845.

20. Okishiro M, Taguchi T, Jin Kim S, Shimazu K, Tamaki Y, Noguchi S: Genetic polymorphisms of CYP2D6*10 and CYP2C19*2, *3 are not associated with prognosis, endometrial thickness, or bone mineral density in Japanese breast cancer patients treated with adjuvant tamoxifen. Cancer 2009, 115:952-961.

21. Wegman $P$, Elingarami $S$, Carstensen J, Stal O, Nordenskjold B, Wingren S: Genetic variants of CYP3A5, CYP2D6, SULT1A1, UGT2B15 and tamoxifen response in postmenopausal patients with breast cancer. Breast Cancer Res 2007, 9:R7.

22. Wegman P, Vainikka L, Stal O, Nordenskjold B, Skoog L, Rutqvist LE, Wingren S: Genotype of metabolic enzymes and the benefit of tamoxifen in postmenopausal breast cancer patients. Breast Cancer Res 2005, 7:R284-290.

23. Nowell SA, Ahn J, Rae JM, Scheys JO, Trovato A, Sweeney C, MacLeod SL, Kadlubar FF, Ambrosone CB: Association of genetic variation in tamoxifen-metabolizing enzymes with overall survival and recurrence of disease in breast cancer patients. Breast Cancer Res Treat 2005, 91:249-258.
24. Toyama T, Yamashita $H$, Sugiura $H$, Kondo $N$, Iwase $H$, Fujii $Y$ : No association between CYP2D6*10 genotype and survival of nodenegative Japanese breast cancer patients receiving adjuvant tamoxifen treatment. Jpn J Clin Oncol 2009, 39:651-656.

25. Rae JM, Drury S, Hayes DF, Stearns V, Thibert JN, Haynes BP, Salter J, Pineda S, Cuzick J, Dowsett M: Lack of correlation between gene variants in tamoxifen metabolizing enzymes with primary endpoints in the ATAC trial [abstract]. Cancer Res 2010, 70(Suppl 2):nr S1-7.

26. Leyland-Jones B, Regan MM, Bouzyk M, Kammler R, Tang W, Pagani O, Maibach R, Dell'Orto P, Thurlimann B, Price KN, Viale G, Group. B-CGalBCS: Outcome according to CYP2D6 genotype among postmenopausal women with endocrine-responsive early invasive breast cancer randomized in the BIG 1-98 trial [abstract]. Cancer Res 2010, 70(Suppl 2): nr S1-8.

27. Cuzick J, Sestak I, Baum M, Buzdar A, Howell A, Dowsett M, Forbes JF: Effect of anastrozole and tamoxifen as adjuvant treatment for earlystage breast cancer: 10-year analysis of the ATAC trial. Lancet Oncol 2010, 11:1135-1141.

28. Colleoni M, Giobbie-Hurder A, Regan MM, Thurlimann B, Mouridsen H, Mauriac L, Forbes JF, Paridaens R, Lang I, Smith I, Chirgwin J, Pienkowski T, Wardley A, Price KN, Gelber RD, Coates AS, Goldhirsch A: Analyses adjusting for selective crossover show improved overall survival with adjuvant letrozole compared with tamoxifen in the BIG 1-98 study. J Clin Oncol 2011, 29:1117-1124.

29. Li Cl, Daling JR, Malone KE: Incidence of invasive breast cancer by hormone receptor status from 1992 to 1998. J Clin Oncol 2003, 21:28-34

30. Jassem J: Intergroup Exemestane Study mature analysis: overall survival data. Anticancer Drugs 2008, 19(Suppl 1):S3-7.

31. Howell A, Cuzick J, Baum M, Buzdar A, Dowsett M, Forbes JF, HoctinBoes G, Houghton J, Locker GY, Tobias JS: Results of the ATAC (Arimidex Tamoxifen, Alone or in Combination) trial after completion of 5 years' adjuvant treatment for breast cancer. Lancet 2005, 365:60-62.

32. Thurlimann B, Keshaviah A, Coates AS, Mouridsen H, Mauriac L, Forbes JF, Paridaens R, Castiglione-Gertsch M, Gelber RD, Rabaglio M, Smith I, Wardley A, Price KN, Goldhirsch A: A comparison of letrozole and tamoxifen in postmenopausal women with early breast cancer. $N$ Engl J Med 2005, 353:2747-2757.

33. Goss PE, Ingle JN, Martino S, Robert NJ, Muss HB, Piccart MJ, Castiglione M, Tu D, Shepherd LE, Pritchard KI, Livingston RB, Davidson NE, Norton L, Perez EA, Abrams JS, Cameron DA, Palmer MJ, Pater JL: Randomized trial of letrozole following tamoxifen as extended adjuvant therapy in receptor-positive breast cancer: updated findings from NCIC CTG MA.17. J Natl Cancer Inst 2005, 97:1262-1271.

34. Colleoni M, Gelber S, Goldhirsch A, Aebi S, Castiglione-Gertsch M, Price KN, Coates AS, Gelber RD: Tamoxifen after adjuvant chemotherapy for premenopausal women with lymph node-positive breast cancer: International Breast Cancer Study Group Trial 13-93. J Clin Oncol 2006, 24:1332-1341.

35. Cuzick J, Ambroisine L, Davidson N, Jakesz R, Kaufmann M, Regan M, Sainsbury R: Use of luteinising-hormone-releasing hormone agonists as adjuvant treatment in premenopausal patients with hormone-receptorpositive breast cancer: a meta-analysis of individual patient data from randomised adjuvant trials. Lancet 2007, 369:1711-1723.

36. Gnant M, Mlineritsch B, Schippinger W, Luschin-Ebengreuth $G$ Postlberger S, Menzel C, Jakesz R, Seifert M, Hubalek M, Bjelic-Radisic V, Samonigg H, Tausch C, Eidtmann H, Steger G, Kwasny W, Dubsky P, Fridrik M, Fitzal F, Stierer M, Rucklinger E, Greil R, Marth C: Endocrine therapy plus zoledronic acid in premenopausal breast cancer. N Engl J Med 2009, 360:679-691.

37. Puhalla S, Brufsky A, Davidson N: Adjuvant endocrine therapy for premenopausal women with breast cancer. Breast 2009, 18(Suppl 3): S122-130.

38. Rebsamen MC, Desmeules J, Daali Y, Chiappe A, Diemand A, Rey C, Chabert J, Dayer P, Hochstrasser D, Rossier MF: The AmpliChip CYP450 test: cytochrome P450 2D6 genotype assessment and phenotype prediction. Pharmacogenomics J 2009, 9:34-41.

39. Flockhart DA: Drug Interactions: Cytochrome P450 Drug Interaction Table. Indiana University School of Medicine.[http://medicine.iupui.edu/ clinpharm/ddis/table.aspx].

40. Smith IE, Dowsett M, Yap YS, Walsh G, Lonning PE, Santen RJ, Hayes D: Adjuvant aromatase inhibitors for early breast cancer after 
chemotherapy-induced amenorrhoea: caution and suggested guidelines. J Clin Oncol 2006, 24:2444-2447.

41. Seruga B, Amir E: Cytochrome P450 2 D6 and outcomes of adjuvant tamoxifen therapy: results of a meta-analysis. Breast Cancer Res Treat 2010, 122:609-617.

42. Kiyotani K, Mushiroda T, Imamura CK, Hosono N, Tsunoda T, Kubo M, Tanigawara Y, Flockhart DA, Desta Z, Skaar TC, Aki F, Hirata K, Takatsuka Y, Okazaki M, Ohsumi S, Yamakawa T, Sasa M, Nakamura Y, Zembutsu H: Significant effect of polymorphisms in CYP2D6 and ABCC2 on clinical outcomes of adjuvant tamoxifen therapy for breast cancer patients. J Clin Oncol 2010, 28:1287-1293.

43. Borges S, Desta Z, Li L, Skaar TC, Ward BA, Nguyen A, Jin Y, Storniolo AM, Nikoloff DM, Wu L, Hillman G, Hayes DF, Stearns V, Flockhart DA: Quantitative effect of CYP2D6 genotype and inhibitors on tamoxifen metabolism: implication for optimization of breast cancer treatment. Clin Pharmacol Ther 2006, 80:61-74.

44. Sideras K, Ingle JN, Ames MM, Loprinzi CL, Mrazek DP, Black JL, Weinshilboum RM, Hawse JR, Spelsberg TC, Goetz MP: Coprescription of tamoxifen and medications that inhibit CYP2D6. J Clin Oncol 2010, 28:2768-2776

45. Skinner MH, Kuan HY, Pan A, Sathirakul K, Knadler MP, Gonzales CR, Yeo KP, Reddy S, Lim M, Ayan-Oshodi M, Wise SD: Duloxetine is both an inhibitor and a substrate of cytochrome P4502D6 in healthy volunteers. Clin Pharmacol Ther 2003, 73:170-177.

46. Kotlyar M, Brauer LH, Tracy TS, Hatsukami DK, Harris J, Bronars CA Adson DE: Inhibition of CYP2D6 activity by bupropion. J Clin Psychopharmacol 2005, 25:226-229.

47. Hill CE, Duncan A: Overview of pharmacogenetics in anticoagulation therapy. Clin Lab Med 2008, 28:513-524.

48. Mahajan P, Meyer KS, Wall GC, Price HJ: Clinical applications of pharmacogenomics guided warfarin dosing. Int $J$ Clin Pharm 2011, 33:10-19.

49. Evans DG, Lalloo F, Ashcroft L, Shenton A, Clancy T, Baildam AD, Brain A, Hopwood $P$, Howell A: Uptake of risk-reducing surgery in unaffected women at high risk of breast and ovarian cancer is risk, age, and time dependent. Cancer Epidemiol Biomarkers Prev 2009, 18:2318-2324.

50. Domchek SM, Friebel TM, Singer CF, Evans DG, Lynch HT, Isaacs C, Garber JE, Neuhausen SL, Matloff E, Eeles R, Pichert G, Van t'veer L, Tung N, Weitzel JN, Couch FJ, Rubinstein WS, Ganz PA, Daly MB, Olopade OI, Tomlinson G, Schildkraut J, Blum JL, Rebbeck TR: Association of riskreducing surgery in BRCA1 or BRCA2 mutation carriers with cancer risk and mortality. JAMA 2010, 304:967-975.

51. Beattie MS, Crawford B, Lin F, Vittinghoff E, Ziegler J: Uptake, time course, and predictors of risk-reducing surgeries in BRCA carriers. Genet Test Mol Biomarkers 2009, 13:51-56.

52. Gabriel CA, Tigges-Cardwell J, Stopfer J, Erlichman J, Nathanson K, Domchek SM: Use of total abdominal hysterectomy and hormone replacement therapy in BRCA1 and BRCA2 mutation carriers undergoing risk-reducing salpingo-oophorectomy. Fam Cancer 2009, 8:23-28.

53. Quinn GP, Vadaparampil ST, McGowan Lowrey K, Eidson S, Knapp C, Bukulmez O: State laws and regulations addressing third-party reimbursement for infertility treatment: implications for cancer survivors. Fertil Steril 2011, 95:72-78.

doi:10.1186/gm280

Cite this article as: Lorizio et al:: Pharmacogenetic testing affects choice of therapy among women considering tamoxifen treatment. Genome Medicine 2011 3:64

\section{Submit your next manuscript to BioMed Central and take full advantage of:}

- Convenient online submission

- Thorough peer review

- No space constraints or color figure charges

- Immediate publication on acceptance

- Inclusion in PubMed, CAS, Scopus and Google Scholar

- Research which is freely available for redistribution 